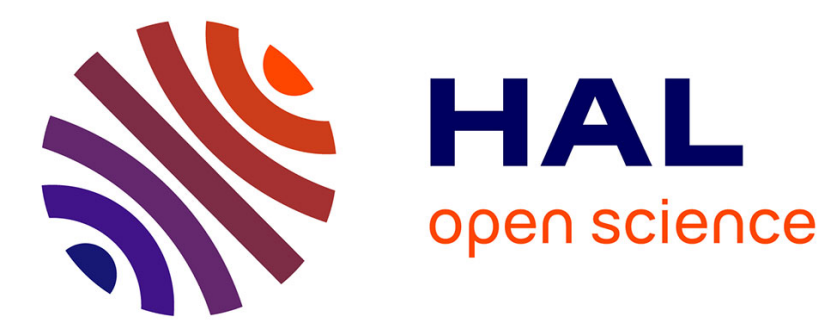

\title{
Planning cordless business communication systems
}

Thom Fruehwirth, Pascal Brisset, Joerg-Rainer Molwitz

\section{To cite this version:}

Thom Fruehwirth, Pascal Brisset, Joerg-Rainer Molwitz. Planning cordless business communication systems. IEEE Expert, 1996, 11 (1), pp 50-55. 10.1109/64.482958 . hal-00914546

\section{HAL Id: hal-00914546 \\ https://hal-enac.archives-ouvertes.fr/hal-00914546}

Submitted on 5 Dec 2013

HAL is a multi-disciplinary open access archive for the deposit and dissemination of scientific research documents, whether they are published or not. The documents may come from teaching and research institutions in France or abroad, or from public or private research centers.
L'archive ouverte pluridisciplinaire HAL, est destinée au dépôt et à la diffusion de documents scientifiques de niveau recherche, publiés ou non, émanant des établissements d'enseignement et de recherche français ou étrangers, des laboratoires publics ou privés. 


\section{Planning Cordless Business Communication Systems}

Thom Frühwirth and Pascal Brisset, European Computer-Industry Research Center Jörg-Rainer Molwitz, Siemens

\section{(2)} communicating through their mobile phones. Wireless communication might be the trend of the nineties, and it definitely means big business for the telecommunication industry. In Germany, for example, every third phone sold today is mobile. In the US, there will soon be 20 million subscribers to cellular phone services. In the second half of the nineties, $20 \%$ to $30 \%$ of phones sold worldwide are expected to be wireless (see Figure 1). ${ }^{1}$

The introduction of a European standard for digital cordless telecommunication has made cordless local area networks possible. Mobile communication can come to company sites. No cabling is required, and the employees can be reached anytime at any place. However, planning wireless digital networks is quite different from planning traditional wire-based systems. The plan must account for the specifics of radio-wave propagation at the installation site. Computeraided planning promises to ease some of the difficulties.

In this article, we describe Popular (Planning of Picocellular Radio), a prototype tool resulting from a collaboration of industry and research institutions in Germany: the Siemens Research and Development Depart-

\author{
The POPUlaR TOOL USES CONSTRAINT-BASED \\ PROGRAMMING TO OPTIMIZE THE PLACEMENT OF BASE \\ STATIONS FOR LOCAL WIRELESS COMMUNICATION.
}

ment, the Siemens Personal Networks Department, the European Computer-Industry Research Center (ECRC), and the Institute of Communication Networks at the Aachen University of Technology. ${ }^{2}$ Popular uses a path-loss model to describe radio-wave transmission and constraint-based programming to optimize the placement of base stations (transmitters) for local wireless communication at company sites.

The DECT standard and PABX systems. In 1992, the European Telecommunications Standards Institute published the Digital European Cordless Telecommunications standard. ${ }^{3}$ The DECT standard enables radio networks with a cellular structure. A radio cell is the space that a transmitter (base station) covers. A cell's radius is usually tens of meters. Buildings require multicellular systems, because walls and floors absorb part of the radio signal. In a DECT network, a receiver can automatically switch to a different sender during communication (seamless handover) and change the carrier frequency to improve the transmission's quality (that is, the network is a seamless multicarrier system).

The standard integrates a number of telecommunication services. The wireless services include the Telepoint service (for public phones in cities), local area networks for data transfer, and Private Automatic Branch Exchanges (PABX) for in-house communication. In this article we'll discuss PABX systems (see Figure 2).

The market for PABX systems is growing 
even faster than the wireless communication market. PABX enables the installation of cordless business communication systems. The major vendors of PABX systems based on the DECT standard are Alcatel (Alcatel 4220/4000), Ericsson (Freeset), and Siemens (Hicom Cordless 300).

Computer-aided planning can help. Of course, selling such systems is not enough; the service that comes with it makes the difference. A vendor also plans, installs, and maintains the system. The planning phase is especially important, because a vendor that can offer to cover a company site with fewer base stations will be ahead of its competition.

Today, an experienced salesperson estimates the number and positioning of base stations. To assist, Siemens has compiled a set of guidelines based on typical scenarios. However, a scenario might not always apply, and the approach does not work well for positioning the base stations.

The next step to improve customer satisfaction and to minimize sales costs is com puter-aided planning. The idea is straightforward: given a blueprint of the building or company site, compute the minimal number of base stations and their location by simulation and subsequent optimization.

\section{Modeling picocellular radio}

To simulate a cordless business communication system, we need to model picocellular (smaller cell) radio transmission and the building that will house the system. The model might have to account for these impediments to radio-wave transmission:

- attenuation (weakening) of the signal caused by distance,

- shadowing (absorption) through obstacles,

- multipath propagation caused by reflection and diffraction,

- interference with other transmitters, and

- motion in the radio field (the Doppler effect).

Path-loss model. A path-loss model can describe indoor radio propagation at a macroscopic level. Homayoun Hashemi writes:

Path loss information in indoor environments are essential in determination of the size of the coverage area for radio communications systems, and in selecting optimum locations for base antennas. Obtaining three-dimensional

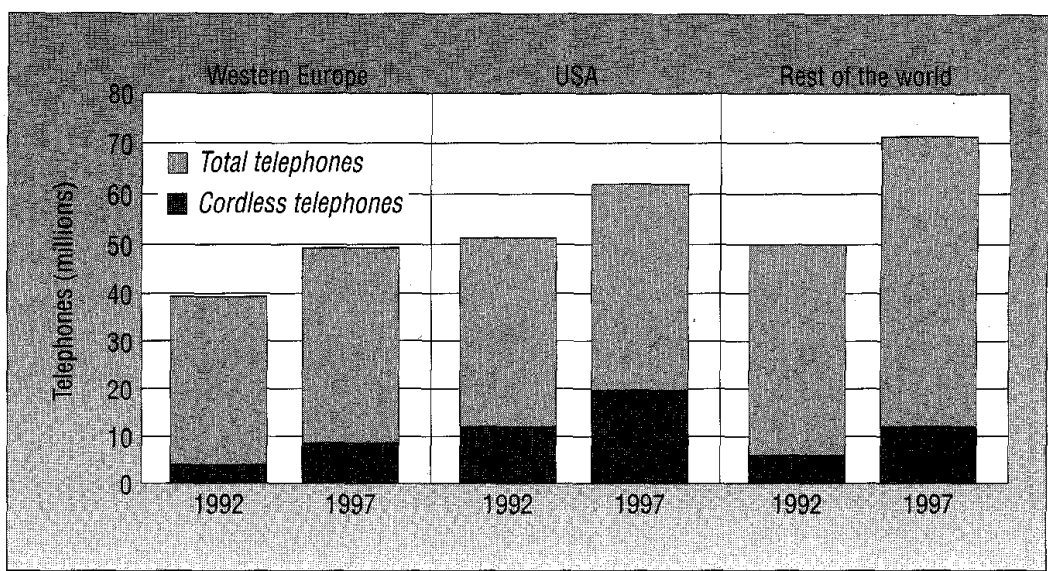

Figure 1. Sales of telephones.

propagation contour plots using a building's blue-print and the knowledge of its construction material is a challenging job which requires detailed and reliable path loss models. ${ }^{4}$

The European Cooperation in the field of Scientific and Technical Research (COST) Propagation Models subgroup proposed this path-loss model: ${ }^{5}$

$L_{P}=L_{1 m}+10 n \log _{10} d+\sum_{i} k_{i} F_{i}+\sum_{i} p_{j} W_{j}$

$L_{P}$ is the total path loss in decibels. $L_{1 m}$ is the path loss one meter from the transmitter. $n$ is the propagation factor. $d$ is the distance between the transmitter and receiver. $k_{i}$ is the number of floors of kind $i$ in the propagation path. $F_{i}$ is the attenuation factor of one floor of kind $i . p_{j}$ is the number of walls of kind $j$ in the propagation path. $W_{j}$ is the attenuation factor of one wall of kind $j$.

The model is based on the power balance of wireless transmission. It combines a distance-dependent term with correction factors for extra path loss caused by the building's floors and walls in the propagation path. Mark Keenan and Andrew Motley found that the following parameters gave the best fit to actual data. ${ }^{6}$ The propagation factor for the indoor radio propagation channel is $n=2$, the same as in the open air. A carrier frequency of $1.728 \mathrm{GHz}$ caused a path loss in 1 meter of $38 \mathrm{~dB}$. Figure 3 (next page) shows typical path loss over distance, on a logarithmic scale. At 6 and 9 meters, walls are weakening the signal.

The walls and floors are characterized by their attenuation factors. The attenuation not only consists of the loss caused by the material, but also includes the loss caused by the limited dimensions of a wall or floor, and by doors, windows, inhomogeneous materials

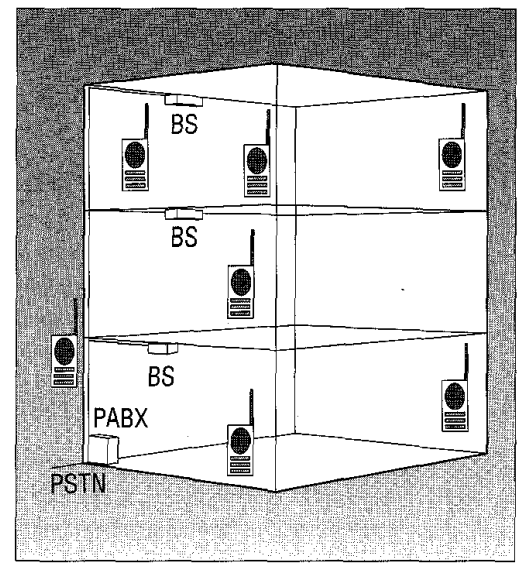

Figure 2. A wireless Private Automatic Branch Exchange (PABX) with base stations (BS) and a Public Switched Telephone Network (PSTN).

used, and so on. The overall loss is called insertion loss (see Tables 1 and 2).

Extending the model. The COST path-loss model does not account for reflection and hence multipath effects. Even with sufficient receiver sensitivity, a radio link could fail because of fading and the excessive bit errors that fading causes. However, directly accounting for this would complicate the model considerably and introduce new sources of imprecision. So, we introduce a fading reserve (fade margin). Investigations into bit-error probability independent of multipath effects show that a DECT multicarrier system behaves well compared to a single-carrier system. ${ }^{7,8}$ Accordingly, we choose a fading reserve appropriate to the expected number of bit errors.

The COST model also does not account 


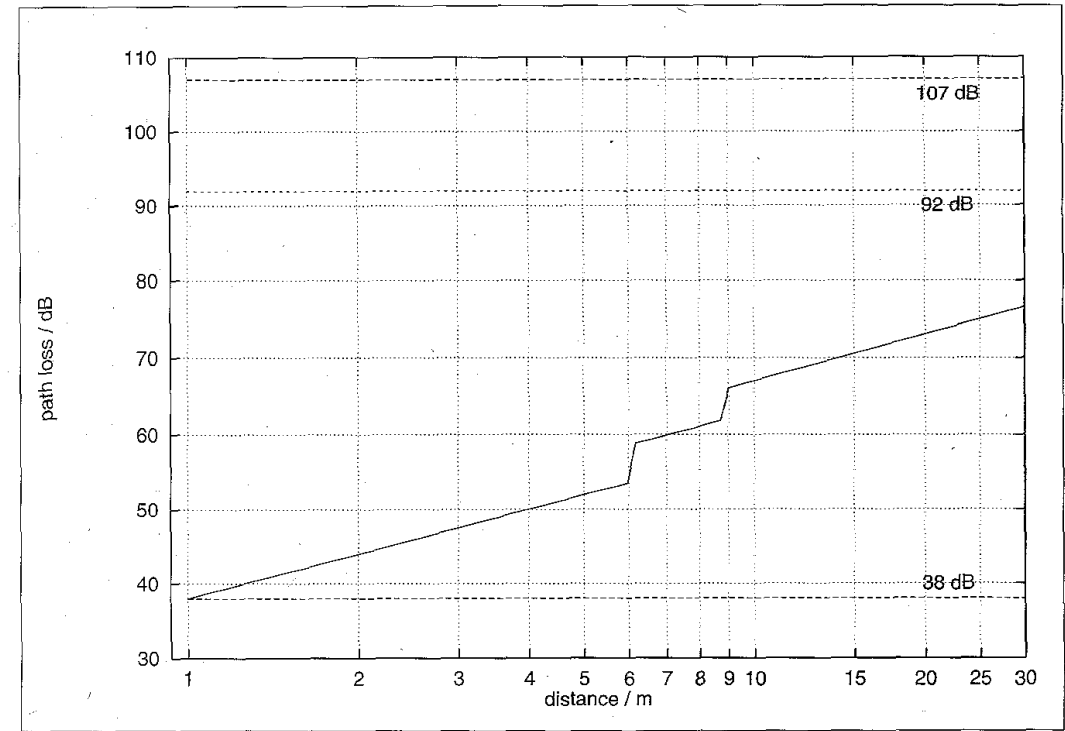

Figure 3. Typical path loss with additional attenuation at 6 and 9 meters caused by walls.

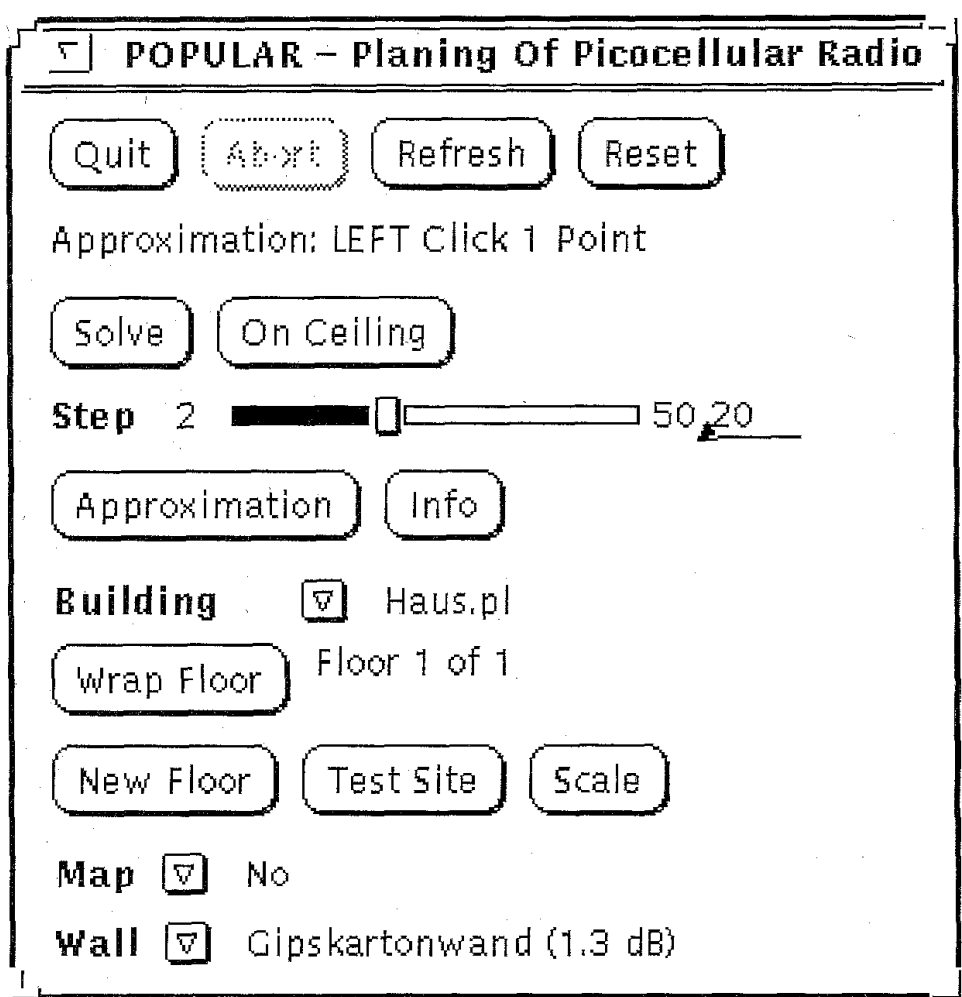

Figure 4. Popular's control panel.

for an antenna's directional effect. Antennas do not transmit the same amount of energy in every direction. Gain, $G$, describes the di- (a hypothetical antenna that broadcasts and receives signals in all directions equally). The radiation density depends on the polar angles $\rho$ and $\phi$ and is adapted to the maximal density. It is usually expressed as the directional diagram, $S(\rho, \phi) / S_{\max }$. For the directivity of an antenna,

$$
G(\rho, \phi)=G \cdot \frac{S(\rho, \phi)}{S_{\max }}
$$

Our extended path-loss model combines Equations 1 and 2:

$$
\begin{aligned}
L_{P^{\prime}}= & L_{p}+L_{\text {FadingReserve }}- \\
& 10 \log _{10}(G)-10 \log _{10}\left(\frac{S(\rho, \phi)}{S_{\max }}\right)(3)
\end{aligned}
$$

Our path-loss model does not need to account for interference with other transmitters or for the Doppler effect. The cordless communication system can automatically change to a better frequency, and the system uses such high frequencies that the Doppler shift is negligible.

Precision of the extended model. Siemens' Public Networks and Personal Networks departments did experiments concerning Last Mile applications of DECT-based telecommunication systems. (Last Mile systems replace traditional local cable-based communication with wireless communication.) The standard deviation between the actual measurements and the prediction based on the standard path-loss model was $4 \mathrm{~dB}$. Other researchers-for example, Keegan and Motley ${ }^{6}$-report similar results.

This imprecision occurs because the standard model does not account for fading and because it imprecisely handles signal loss. The extended model's fading reserve can account for the worst case caused by this imprecision. Our model is precise within a few meters. Although this accuracy seems satisfactory, we need to consider multipathpropagation effects in more detail. This would let us estimate the bit-error rates and thus refine the computation of the radio cells.

\section{Planning in Popular}

Pascal Brisset and Jörg-Rainer Molwitz implemented Popular in one man-year, using the ECRC Constraint Logic Programming System (Eclipse). ${ }^{9}$ Eclipse is a rule-based system that uses constraints ${ }^{10}$ to express partial information and preconditions and post- 
Table 1. Insertion loss from walls. ${ }^{5}$ (Soft-system walls are similar to plaster-cardboard walls and are often used in office interiors.)

\begin{tabular}{lc}
\hline Wall constauction & $L_{\text {ins }}(\mathrm{dB})$ \\
\hline Soft-system wall & $2-3$ \\
Glass & 2 \\
Reinforced glass & 8 \\
70-cm brick & $4-5$ \\
100-cm brick & 9 \\
10-cm concrete, indoor & 6 \\
20-cm concrete, large windows & $5-6$ \\
40-cm concrete, indoor & 17 \\
Steel, large reinforced windows & 10 \\
\hline
\end{tabular}

Table 2. Insertion loss from ceilings. ${ }^{5}$

\begin{tabular}{lc}
\hline Celling Construction & $L_{\text {ins }}(\mathbf{d B})$ \\
\hline Reinforced concrete & $6-9$ \\
Tiles and metal mesh & 15 \\
Reinforced concrete on & $12-16$ \\
steel frame & \\
\hline
\end{tabular}

conditions on rules. Eclipse 3.4 incorporates constraint-handling rules ${ }^{11}$ which were essential in implementing Popular. Constrainthandling rules are a high-level language extension to implement arbitrary constraint systems. They allowed rapid, flexible, and efficient implementation of the placement problem's geometric constraints. Figure 4 shows Popular's control panel.

Popular starts with basic information about the building or company site (such as a blueprint and the materials used for walls and ceilings). The precision of a blueprint is usually sufficient, because the modeling of radio transmission is the main source of imprecision. Because a wall and ceiling can only have a single degree of attenuation, buildings with heterogeneous walls and ceilings may have to be approximated piecewise.

Given this information, Popular simulates the installation of base stations (transmitters) and optimizes the installation to find the minimal number of base stations and their location.

Simulation of radio cells. First, we compute the building's characteristics, using test points. Each test point represents a possible receiver position. Assuming that the radio

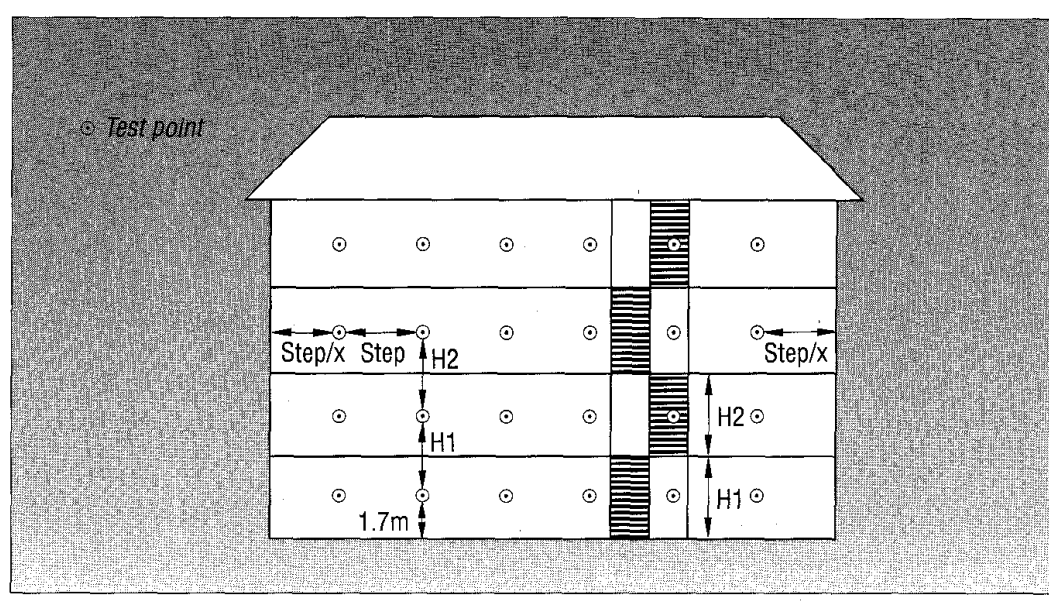

Figure 5. Grid of test points in a building.

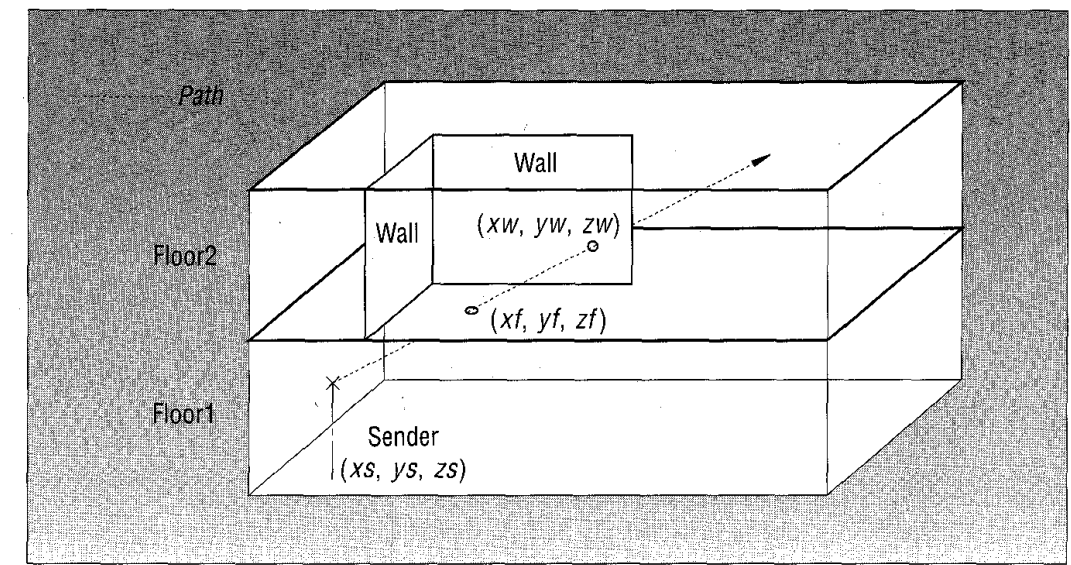

Figure 6. Path from transmitter intersecting a ceiling and a wall.

channel is reciprocal, we can interchange transmitters and receivers. We place the test points on a 3D grid inside the volume that should be covered. The user chooses the horizontal distances of the test points, which are approximately 3-8 meters. Each floor of the building has one such layer of test points (see Figure 5)

Popular then calculates the radio cell for each test point. To cover a test point, a base station must be placed inside its cell. If the grid is sufficiently small, we can expect that if two neighboring test points are covered, the space in between is also covered. Hence, the whole building will be covered.

To calculate cells, Popular uses lowresolution path tracing. The current implementation uses 128 discrete unit vectors as directions. To get to the point of minimal sensitivity (that is, maximal permissible path loss), each path must be followed through the whole building (see Figure 6). To determine the maximal permissible path loss, Popular adds the values of antenna attenuation in the direction of the path, the path loss caused by the distance, and the insertion losses caused by intersections of the path with walls and floors. The resulting endpoints describe the boundaries of the radio cell.

In practice, the base stations are installed at the same height from the floor on the ceilings or on the walls. This means that on each floor, the possible space of locations for base stations is on a single plane. This plane intersects with the radio cells, reducing them from a polyhedron to a series of connected planes (one for each floor) (see Figure 7).

Constraint-based optimization. Popular uses Eclipse to optimize the number and 


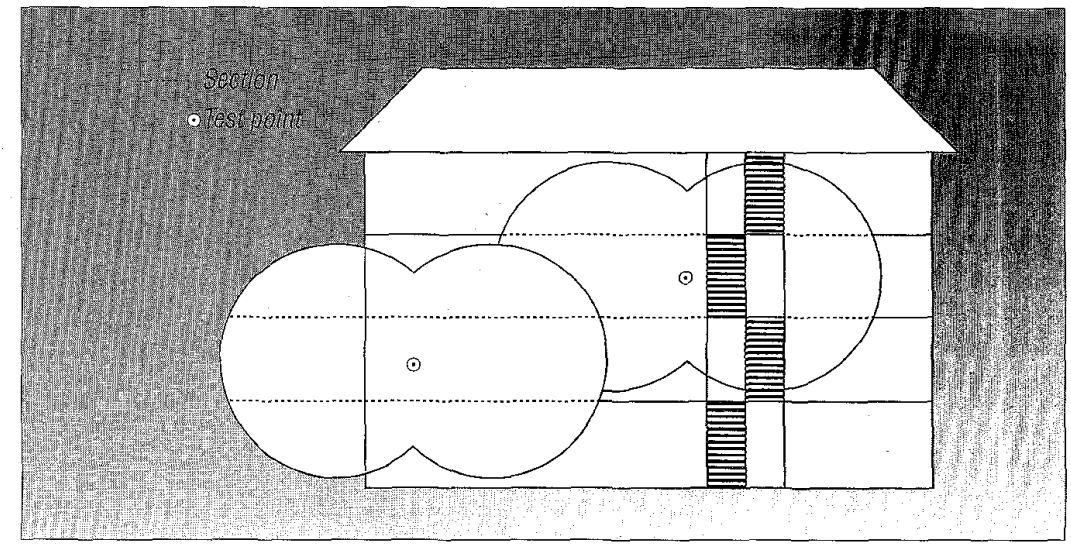

Figure 7. Typical radio coverage areas in a building.

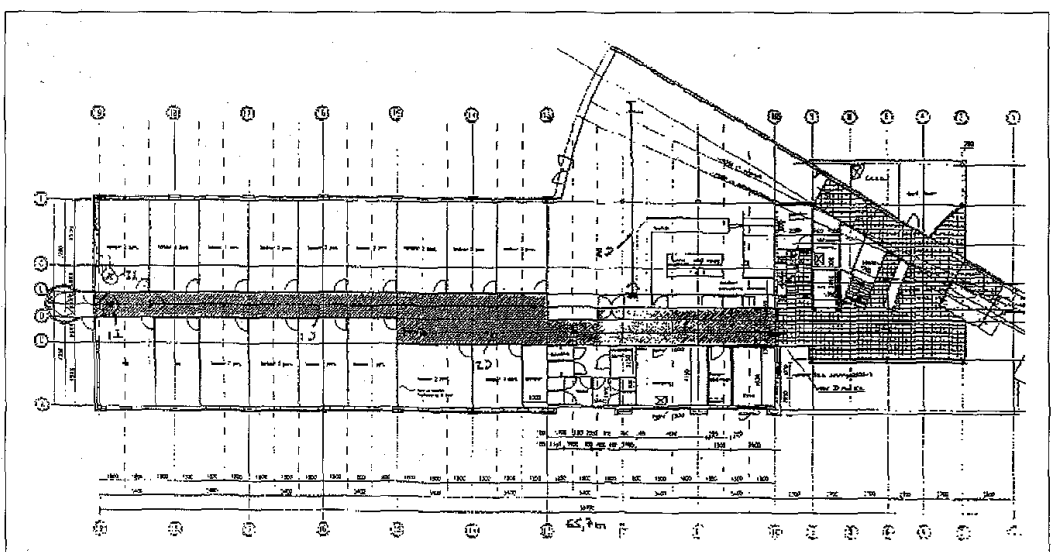

Figure 8. Blueprint of an office building in the Netherlands.

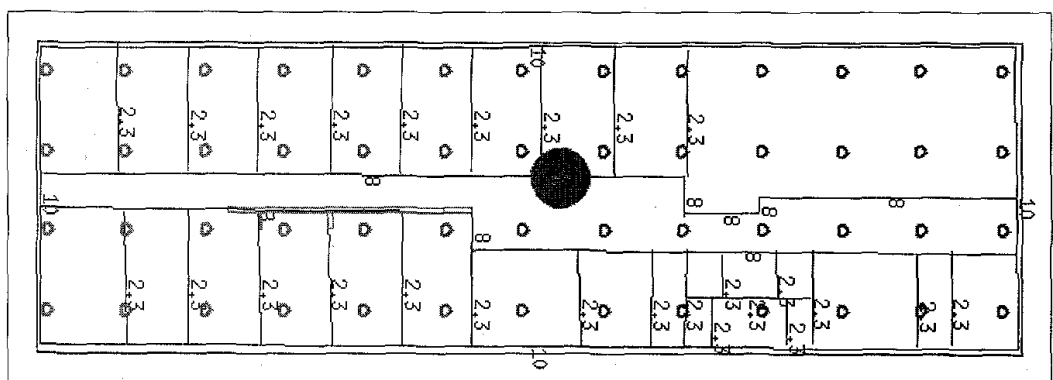

Figure 9. Solution of the planning problem with a test-point grid size of four meters. Dotted lines indicate the possible locations; the circle indicates the location chosen by Popular.

placement of senders. For each radio cell (that is, its set of planes), we set up the constraint that at least one location of a base station (geometrically speaking, a point) must be somewhere in that area. Then, Popular tries to find locations that are in as many radio cell planes as possible at the same time.
Thus, the possible locations are constrained planes covered. In this way Popular computes a first solution.

To minimize the number of base stations, Popular uses a branch-and-bound method. This method repeatedly searches for a soluto be in the intersections of the radio cell tion, using progressively smaller numbers of base stations, until it finds the minimal number.

A practical application of Popular. We'll now show how Popular determines the optimal placement of base stations for an office building in the Netherlands.Figure 8 shows a blueprint). This single-floor building is approximately 15 by 49 meters, and is approximately three meters high. The inside walls are soft-system walls with an attenuation of $2.3 \mathrm{~dB}$, except for the walls to the hallway, which are stronger, with an attenuation of 8 dB. (Soft-system walls are similar to plastercardboard walls and are often used in office interiors.)

To get a description of the building, we scan in the blueprint. From the scanned image, we redraw the walls and ceilings. Each wall and ceiling gets its own attenuation factor. Also, we define the test site-that is, the volume of the building that must be completely covered by base stations.

To solve this planning problem, we choose a grid size of four meters. We estimated the size from the dimensions of the building's rooms. We constrain base stations to be installed on walls only. Popular places a single base station near the center of the building. Figure 9 shows the possible locations on the walls as dotted lines. Popular has chosen the position indicated by the circle for the base station.

In a slightly different scenario we assume that all walls have the same, stronger attenuation $(2.7 \mathrm{~dB})$. As Figure 10 indicates, one base station is no longer sufficient to cover the building. The figure shows the radio cell as it would be computed in the simulation phase-composed of smallitriangular segments. Along each line drawn from the base station, Popular has computed the sensitivity up to the point of maximal permissible path loss.

Figure 11 shows a solution to the revised scenario, using two base stations. Both base stations cover the middle of the building. In Figure 11, a radio cell extends only as far as its base station provides the stronger signal, so that the area that each base station covers is accurately visualized.

Popular's performance. While the simulation phase has linear complexity for the number of test points; the optimization phase theoretically has exponential complexity. Our experience shows, however, that the actual 
complexity is much lower. The implementation benefits from heuristics that account for the problem's geometric nature. We measured Popular's runtime on a Sun Sparcstation 10 . The average runtime was almost linear for the number of walls and test points, with about 25 milliseconds per wall and per test point. For larger buildings this results in runtimes of approximately one minute. So, the prototype's speed is satisfactory.

\section{P}

OPULAR'S SOLUTIONS ARE COMparable to those of a human expert. It finds an optimal placement in a few minutes at most. More field tests are necessary to see if Popular always finds the minimal number of base stations.

Our current work aims at making the generation of the test points more flexible and automatic. So far, the user must find the right grid size (the coarsest one that still leads to good results) by trial and error. We plan to generate test points automatically, based on the building's architecture.

\section{Acknowledgment}

This research was partly supported by Esprit Project 5291 Constraint Handling in Industry and Commerce (CHIC).

\section{References}

1. J.-R. Molwitz, Entwicklung eines Werkzeugs zur Planung picozellularer Funknetze für die drahtlose Kommunikation (Development of a Tool for Planning Picocellular Radio Net works for Wireless Communication), master's thesis, Univ. of Technology, Aachen, Germany, 1994

2. D. Botsch "Schnurlos, aber doch auf Draht" ("Cordless, but still on wire"), Siemens Zeitschrift, No. 1, 1994, pp. 5-10.

3. Radio Equipment and Systems (RES); Digital European Cordless Telecommunications (DECT); Common Interface; Part 1: Overview, Tech. Report ETS 300 175-1:1992, European Telecommunications Standards Inst., Sophia Antipolis, France, 1992.

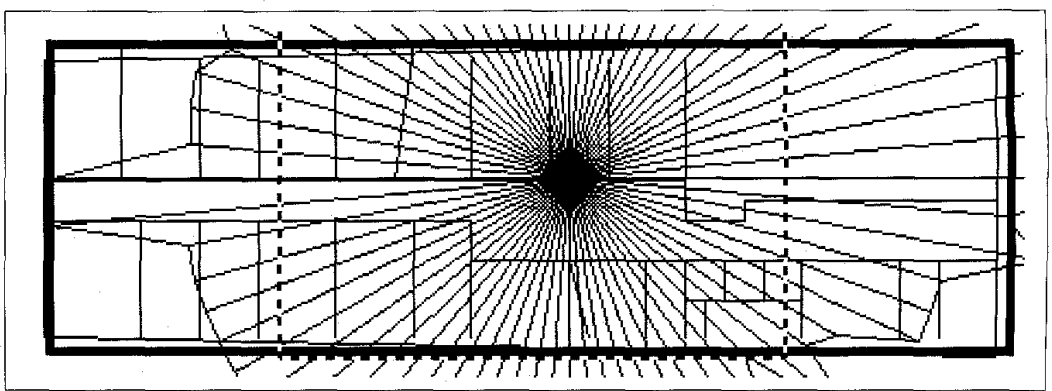

Figure 10. Radio area of one base station if the walls have stronger attenuation than shown in Figure 9.

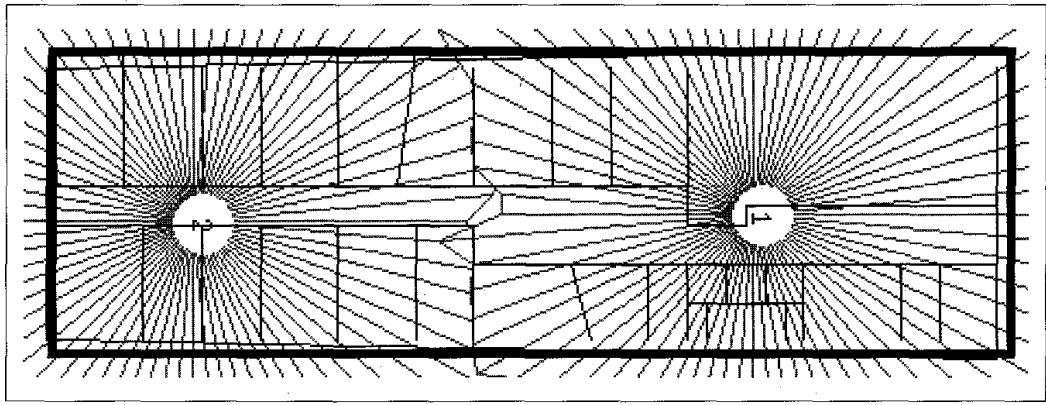

Figure 11. Radio areas of two base stations covering the building with stronger walls.

4. H. Hashemi, "The Indoor Radio Propagation Channel," Proc. IEEE, Vol. 81, No. 7, July 1993, pp. 943-967.

5. COST 231 Propagation Models Subgroup, Building Penetration Losses, Tech. Report TD (90) 116, European Cooperation in the Field of Scientific and Technical Research (COST), Darmstadt, Germany, 1990.

6. J.M. Keenan and A.J. Motley, "Radio Coverage in Buildings," British Telecom Technology J., Vol. 8, No. 1, Jan. 1990, pp. 19-24.

7. L.B. Lopez and M.R. Heath, "The Performance of DECT in the Outdoor $1.8 \mathrm{GHz}$ Radio Channel," Proc. Sixth IEE Conf. Mobile Radio and Personal Communications, Institution of Electrical Engineers, Stevenage, Hertfordshire, United Kingdom, 1991

8. G. Schultes and I. Crohn, "Measured Performance of DECT Transmission in Low Dispersive Indoor Radio Channel," Electronics Letters, Vol. 28, No. 17, Aug. 1992, pp. 1625-1627.

9. P. Brisset et al., Eclipse 3.4 Extensions User Manual, European Computer-Industry Research Center (ECRC), Munich, Germany, 1994 (available by anonymous ftp from ftp.ecrc.de, directory /pub/eclipse/doc).

10. J. Jaffar and M. Maher, "Constraint Logic Programming: A Survey," J. Logic Programming, Vols. 19-20, 1994, pp. 503-581.

11. T. Frühwirth, "Constraint Handling Rules,' Springer Lecture Notes in Computer Science, No. 910, Mar. 1995, pp. 90-107.
Thom Fruihwirth is a researcher at the European Computer-Industry Research Center, where he is developing constraint-handling rules, a language extension for writing constraint systems. His research interests focus on constraint-based programming and innovative applications thereoffor example, intelligent Internet information servers. He received his $\mathrm{MSc}$ and $\mathrm{PhD}$ in computer science from the Technical University of Vienna, and a one-year Fulbright grant to the State University of New York at Stony Brook. He can be contacted at the ECRC, Arabellastrasse 17, D81925 Munich, Germany; thom@ecrc.de; http://www.ecrc.de/staff/thom/.

Jörg-Rainer Molwitz is a project manager at Datus Elektronische Informationssysteme. His research interests focus on mobile and data communication, and the planning and developing of new software facilities for communication systems. He received his MSc in electrical engineering, with a specialization in telecommunications, from the Aachen University of Technology in 1994. He can be reached at Datus Elektronische Informationssysteme GmbH, Tempelhoferstr. 46, D-52068 Aachen, Germany.

Pascal Brisset is a teacher at the Ecole Nationale de l'Aviation Civile. His research interests focus on constraint programming for global optimization. He is particularly interested in comparisons between constraint-based solutions and stochastic methods (that is, genetic algorithms). He received his $\mathrm{PhD}$ in computer science from the University of Rennes, France. He can be contacted at ENAC, 7 Ave. Edouard Belin, BP 4005, F-31055 Toulouse Cedex, France; pbrisset@eis.enac.dgac.fr. 